\title{
Padrões linguísticos do femicídio na imprensa escrita portuguesa ${ }^{1}$
}

\author{
Sílvia Barbosa, Matilde Gonçalves \& Miguel Magalhães \\ CLUNL, NOVA/FCSH
}

\begin{abstract}
:
With this work we intend to analyze the news in the Portuguese media that report femicide and determine the presence of linguistic patterns with an impact on the creation and support of stereotypes and ideological systems. Preliminary data show that there are distinct linguistic patterns (some referring to sexist stereotypes) in the modalization of those involved and the event in news about femicide and show the need for a linguistic approach to fill the studies already developed.
\end{abstract}

Keywords: femicide, news, linguistic patterns, stereotypes, textual genre

Palavras-chave: femicídio, notícias, padrões linguísticos, estereótipos, género textual

\section{Introdução}

Este trabalho surge na sequência de um aumento exponencial de notícias sobre violência, e mais concretamente notícias sobre femicídio (ou feminicídio), como se pode verificar pelos números divulgados para o ano de 2019 com a morte de 30 mulheres e 27 tentativas de femicídios (OMA, 2019) em Portugal.

O tema da violência tem sido alvo de inúmeros trabalhos e dedicação de diversas associações (tais como a União de Mulheres Alternativa e Resposta, a Associação de Mulheres Contra a Violência, a Associação Portuguesa de Apoio à Vítima, a Direção-Geral de Saúde, a Polícia de Segurança Pública, o Observatório Nacional de Violência e Género), mas com preocupações em vertentes sociodemográficas, na saúde, na proteção das vítimas, como também no sentido de fazer respeitar normas e convenções internacionais aprovadas pelos governos nos últimos anos, com uma especial incidência nas vertentes: social, demográfica, da saúde e criminal do fenómeno.

Com base nos dados destas diferentes associações (APAV, 2019), sabe-se que a violência é também um fenómeno de visibilidade, ou seja, sempre houve ocorrências deste fenómeno, mas antes não era noticiado com a mesma frequência (as questões de violência doméstica eram tidas como pertencendo ao foro pessoal e apenas noticiadas quando o crime tinha contornos de violência extrema), nem do mesmo modo. Tendo em conta quer o papel social da comunicação social, enquanto elemento indispensável para a informação, a divulgação e a construção de opinião, quer a sua organização de acordo com a Lei da Imprensa, o Estatuto do Jornalista e o Código Deontológico, pretendemos, no presente trabalho, analisar como o femicídio é textualizado nos meios de comunicação social escrita em Portugal e determinar a presença de padrões linguísticos. Concomitantemente, através da descrição do uso e do funcionamento da língua nas notícias relativas a femicídios, visamos igualmente compreender de que modo as notícias podem ter impacto na criação e sustentação de estereótipos e sistemas ideológicos e consequentemente interferir e afetar a construção da opinião dos leitores. Para tal, foram tidos em conta os seguintes parâmetros de análise: 1) formato textual: notícia, reportagem, breve, entrevista, entre outros, 2) organização do conteúdo informativo: quê/quem/como/quando/porquê; 3) caracterização dos envolvidos e do evento a partir de uma análise do léxico. A análise incide sobre um corpus de textos de caráter noticioso relativos a crimes de femicídio ocorridos em Portugal, onde o agressor é ou foi

\footnotetext{
${ }^{1} \mathrm{O}$ presente trabalho é financiado por fundos nacionais portugueses, através da FCT - Fundação para a Ciência e Tecnologia, como parte do projeto do Centro de Linguística da Universidade NOVA de Lisboa - UID/LIN/03213/2020
} 
cônjuge/parceiro/namorado da vítima (com relação emocional) extraídas quer do repositório digital Arquivo.pt quer de periódicos portugueses.

Para tal, foi realizado um estudo sobre notícias, retiradas de jornais portugueses e do Arquivo.pt. No decorrer desse estudo, apresentamos, no presente artigo, uma amostra das representações do femicídio e dos envolvidos, resultantes da análise do conteúdo noticiado, de como são descritos quer o crime, quer os envolvidos e da organização do texto. A existência de trabalhos já desenvolvidos para outras temáticas (na enologia, Martinez \& Barbosa (2018), na divulgação de ciência, Gonçalves \& Magalhães (2019)) e replicável para o fenómeno em causa sustenta teórica e metodologicamente o presente trabalho.

Estruturalmente, para além da introdução e das reflexões finais, este artigo organiza-se em duas partes, numa primeira onde se abordam sucintamente as questões teóricas e metodológicas, com destaque para a descrição dos géneros textuais que podem estar presentes na atividade jornalística e a apresentação do corpus de análise e, numa segunda parte, a exposição do que se entende por textualização da violência com recurso a vários exemplos possibilitando a extração de padrões linguísticos relevantes para o presente estudo.

\section{Questões teóricas e metodológicas}

Embora haja um número considerável de estudos sobre a questão da violência, estes inserem-se maioritariamente nas áreas do conhecimento da sociologia e dos meios de comunicação; a título de exemplo, destacam-se Wosniak \& McCloskey (2010); Wilcox (2008); Taylor \& Sorenson (2002); Toledo \& Lagos (2014); Souza (2014); Simões (2007); Rodigou, Nazar, Monserrat \& Hunt (2007); Penedo (2003); Neves, Gomes \& Martins (2016); Magalhães-Dias \& Lobo (2016); Coimbra (2007); Chesney-Lind \& Chagnon (2017); Carvalho (2013); Braber (2014); Alvares \& Veríssimo (2016).

A análise de como a violência contra a mulher é tematizada na atividade jornalística portuguesa é ainda pouco explorada no âmbito da linguística. Assim, para focar um aspeto de domínio social como a violência e o modo como é construído linguisticamente, recorreremos a um instrumento, o género textual, para compreender a inter-relação que se estabelece entre a dimensão social e linguística.

\subsection{Géneros textuais na atividade jornalística}

É consensual que a noção de género textual (ou discursivo, dependente do quadro teórico no qual se situa o trabalho) tem ganho relevância nos estudos, em particular na linguística do texto e do discurso, a nível nacional (Coutinho, 2005, 2019; Coutinho e Miranda, 2009; Leal e Gonçalves, 2007; Gonçalves, 2014) e internacional (Adam, 1999, 2008; Bronckart, 1997, 2005; Rastier, 2001; Marcuschi, 2008; Swales, 1990). Das diversas propostas relativas à questão genológica, e sem nos alongarmos sobre esta questão, importa reter que os géneros, enquanto construtos socio-históricos produzidos pelas gerações anteriores e disponíveis sincronicamente no arquitexto, funcionam como modelos de produção e interpretação textual, implicando necessariamente fatores de adequação contextual. Esses fatores intervêm tanto na escolha do género em função do contexto e do objetivo comunicativo, como na adaptação do mesmo pautada pela organização textual e pela seleção das unidades linguísticas.

Determinados pelo modo de produção dos meios de comunicação de massa e pelas manifestações culturais de cada sociedade, os géneros textuais da esfera jornalística assumem um papel importante enquanto formatos textuais, servindo de modelo de produção textual para os jornalistas e de interpretação textual para o leitor e o estudioso. Dos diversos estudos relativos a esta questão, selecionamos o Livro de Estilo do jornal Público e a obra editada por Maltais (2010) L'écriture journalistique sous toutes ses formes para elaborar uma síntese relativa às práticas jornalísticas, que a seguir, apresentamos. 


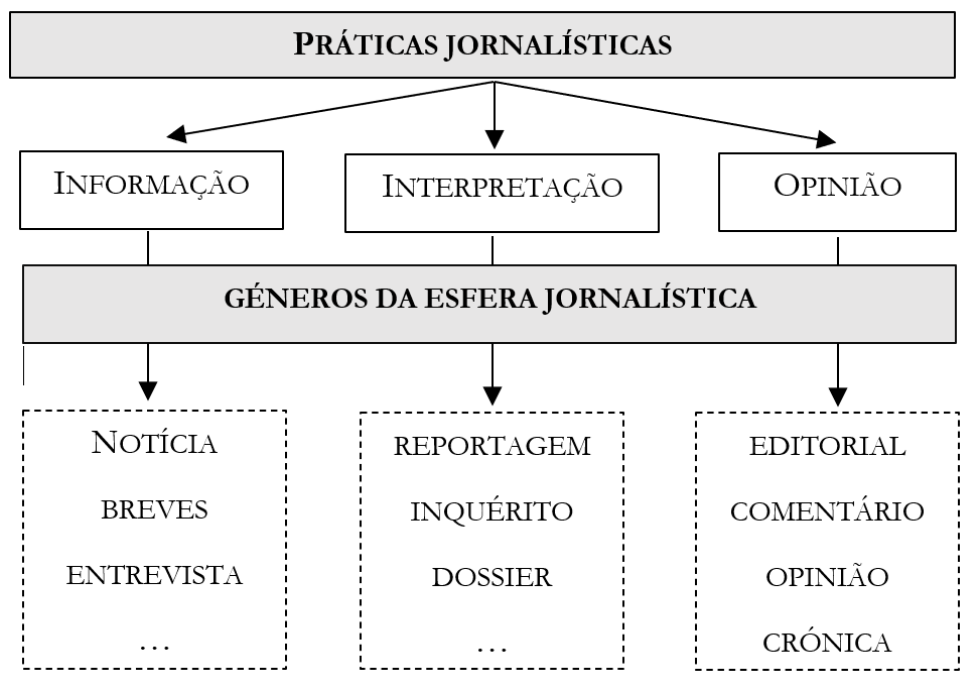

Figura 1. Adaptado de Livro de Estilo do Público e de Maltais (2010)

Por práticas jornalísticas, entendemos os diversos modos de textualizar, ou seja, fazer texto (Adam, 2015), com vista a informar, disseminar, formar e entreter o recetor (podendo este ser leitor, ouvinte ou telespectador). Esses modos de textualização podem ser divididos em três níveis que intervêm na construção das peças jornalísticas: 1) apresentação dos factos que consiste na transmissão de informação, com base na opinião de terceiros; 2) relacionamento dos factos que envolve uma interpretação dos mesmos pelo produtor textual (neste caso jornalista); 3) construção de um juízo de valor sobre os factos transmitindo uma opinião.

De acordo com o exposto anteriormente, importa igualmente realçar a convocação e utilização de géneros textuais diferentes em função desses três níveis. Como se pode atentar no quadro síntese acima, os géneros privilegiados para a apresentação dos factos são a notícia, as breves e a entrevista; para a interpretação dos factos, o produtor recorrerá à reportagem, ao inquérito e ao dossier; finalmente, o editorial, o comentário, a opinião e a crónica são os géneros que enformam a construção de um juízo de valor e de uma opinião.

\subsection{Corpus}

Para a construção de nosso corpus definimos um conjunto de critérios de seleção, recolha, extração e etiquetagem e de análise, como abaixo explicitamos:

- Seleção:

Para a análise, foram selecionados textos com a etiqueta "notícia” aplicada e utilizada pelos próprios jornais.

- Recolha:

Para a recolha, foram extraídos textos noticiosos, quer do repositório digital Arquivo.pt (www.arquivo.pt) quer de periódicos portugueses num período entre 1996 a 2019. O Arquivo.pt permite observar diacronicamente o fenómeno (armazena gratuitamente informação publicada na Web desde 1996), enquanto a recolha em periódicos permite uma visão sincrónica e atual do mesmo.

- Extração:

Para a construção de corpus foram definidos os seguintes parâmetros de extração: 
i. os textos deveriam ser de caráter noticioso relativos a crimes de femicídio;

ii. os crimes deveriam ter ocorridos em Portugal;

iii. os envolvidos tinham uma relação emocional anterior, para descartar outro tipo de relações (para evitar extrair notícias de crimes de mulheres mortas em assaltos, acidentes, entre outros).

- Etiquetagem:

Após a extração de um conjunto de textos, os textos foram etiquetados tendo em conta os seguintes parâmetros:
i. formato textual: notícia (com exclusão da reportagem, breve, entrevista, entre outros);
ii. organização do conteúdo informativo: quê/quem/como/quando/porquê;
iii. caracterização dos envolvidos e do evento a partir de uma análise do léxico.

- Análise:

Após a compilação e tratamento dos textos foi possível:

i. detetar conjuntos de unidades linguísticas (lexicais, semânticas, textuais e discursivas) que possibilitem visualizar/mapear padrões linguísticos;

ii. observar as representações (sociais, culturais, legais, ...);

iii. determinar presença de estereótipos e /ou sistemas ideológicos.

No sentido de detetar a existência de padrões linguísticos, a saber um conjunto de recursos linguísticos recorrentes que edifiquem uma representação estável relativamente à vítima, ao agressor e ao crime, utilizamos um conjunto de ferramentas informáticas para a extração lexical, as frequências, as análises estatísticas, as coocorrências. E, num segundo momento, procedemos à sistematização dos dados recolhidos anteriormente para compreender a organização da notícia, bem como o impacto que pode ter na construção de representações estereotipadas dos diversos agentes envolvidos nas notícias sobre femicídio.

Ainda no tocante à questão das representações estereotipadas, importa destacar os estudos, cada vez mais em voga, sobre o viés linguístico. De facto, estes demonstram como as unidades refletem a influência social e a manutenção dos estereótipos (Beukeboom \& Burgers (2017); Borchmann, Levisen \& Schneider (2019)). A existência desses estudos comprova a necessidade de compreender de que modo os vieses modelam a nossa perceção, o julgamento e a interação com o mundo e com os seres humanos, e de que forma podem criar discriminações. Para além dos estudos sobre viés, que tratam de aspetos a um nível mais específico, interessa ainda, referir trabalhos sobre ideologia, em particular Fairclough (1994), van Dijk (2014) e Volochinov (1929/1977). De facto, esta noção equivale a um conjunto de crenças partilhadas socialmente, circulando a um nível global, cristalizadas e veiculadas pelo uso da língua. De entre os estudos referidos, destacamos, em particular, o trabalho de Volochinov sobre a ideologia do signo linguístico (1929/1977). De facto, este autor estabeleceu uma distinção entre sistemas ideológicos constituídos e a ideologia do quotidiano (ou psicologia social). No primeiro caso, trata-se de "uma superestrutura situada imediatamente acima da base económica." (Volochinov, 1977: 22), correspondendo às "esferas da criação ideológica" - a religião, a ciência, a arte, a moral etc. Caracterizam-se, igualmente, por serem os mais fortemente sistematizados, como o próprio nome indica. No segundo caso, esta enforma-se no discurso interior acerca da vida cotidiana e corresponde a um domínio com pouca ou nenhuma sistematização, ao contrário dos sistemas ideológicos constituídos. Diversos são os géneros, destacados por Volochinov, que contribuem para a criação da ideologia do quotidiano, a saber as conversas de corredor, as trocas de opinião no café, as reuniões sociais, a conversa diária sobre os acontecimentos da vida e o discurso/monólogo interior. Para este autor, os sistemas ideológicos constituídos e a ideologia do quotidiano mantêm relações dialéticas. Os objetos (discursivos) que surgem na ideologia do quotidiano formam o material sobre o qual incidem os sistemas ideológicos constituídos, através da sua 
sistematização, estabilização e conclusão. A ideologia do quotidiano recebe de volta esses objetos sistematizados e acabados e é assim determinada por eles.

Quer os vieses, quer as ideologias, podem ter, como destacado pelos autores acima referenciados, consequências positivas, transmitindo e construindo um sistema de crenças agregador e benéfico para a sociedade, ou negativas, veiculando um conjunto de representações discriminativas. De acordo com o papel social dos meios de comunicação na informação, formação e entretenimento das pessoas, é premente que a textualização da violência não veicule conteúdos que contribuam para a criação e disseminação de representações prejudiciais para os agentes envolvidos.

\section{Textualização da violência}

Nesta secção, realizar-se-á uma análise de cunho qualitativo, focando exemplos relevantes extraídos do corpus recolhido para este estudo.

Embora exista variabilidade no conteúdo noticioso dos textos do corpus, os aspetos apresentados no exemplo a seguir são recorrentes. No exemplo 1, é possível observar que a textualização do crime segue uma organização pautada pelo género notícia, com aspetos factuais de ordem contextual, $\boldsymbol{o}$ qu$\hat{\boldsymbol{e}}$ - crime de situação doméstica; quem - uma mulher; como - foi assassinada; quando - quinta-feira; por quem - marido. Há ainda informação relativa ao onde (detalhe onde vive) e a presunção de inocência (alegadamente).

(1) Uma mulher foi assassinada nesta quinta feira, na casa onde residia, em Vanicelos, no Bairro do Liceu em Setúbal, alegadamente pelo marido, numa situação doméstica que perpetua a elevada tendência para este crime registada no ano passado na região. [Público 22/10/2015; secção notícia]

Na secção que se segue apresentamos alguns exemplos de títulos ou de corpos de notícias (de diversos jornais portugueses) que agrupamos em casos (1 e 2) para evidenciar formas de variabilidade do caráter factual das notícias sobre o femicídio.

\section{Caso 1}

Com os exemplos (2), (3) e (4) apresentamos os títulos de um mesmo crime abordado em três jornais e nos quais se pode observar uma grande variabilidade na textualização do crime: 
(2)

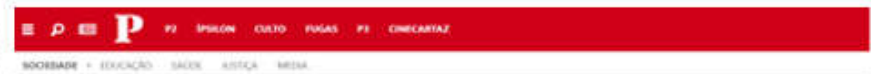

\section{Detido suspeito de ter matado mulher encontrada em mala de viagem}

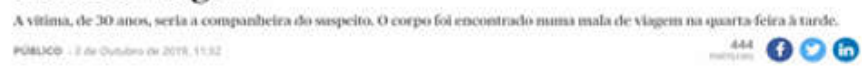

(3)

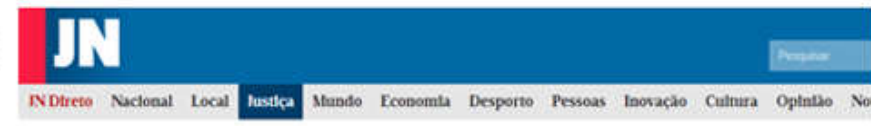

Arruda des Vinhos

Detido homem que matou e abandonou corpo de mulher em Arruda dos Vinhos

(4)

\section{ECII PORTUGAL \\ Mulher encontrada morta em mala com vestido leve, simples e barato}

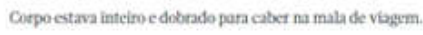

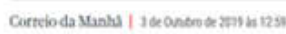

Retomando os aspetos relativos ao conteúdo noticioso apresentados no exemplo (1), é de realçar a discrepância no modo de textualizar o tópico da vítima "mulher encontrada em mala de viagem", "o corpo de mulher" e "mulher encontrada em mala com vestido leve, simples e barato". Nos três exemplos, a vítima aparece em posição de tema num caso, e em rema em três casos.

A análise dos títulos mostra várias estratégias de focalização:

(2) Detido suspeito de ter matado mulher encontrada em mala de viagem

(3) Detido homem que matou e abandonou corpo de mulher em Arruda dos Vinhos

(4) Mulher encontrada morta em mala com vestido leve, simples e barato.

De um modo global, nestes exemplos é possível extrair informação relativa aos seguintes campos apenas com a informação dos títulos e dos leads:

- informação sobre a vítima: mulher (2), (4); corpo de mulher (3)

- informação sobre o que aconteceu: foi encontrada (2), foi abandonada (3), morta (4)

- informação sobre o agressor suspeito (2), homem (3)

- informação sobre o crime: ter matado (2), matar e abandonar corpo (3), morta (4)

- informação sobre a localização do crime: Arruda dos vinhos (2), (3); mala de viagem (2), (4)

- informação adicional sobre a vítima: 30 anos (2), com vestido leve, simples e barato (corpo inteiro e dobrado) (4) 
Relativamente às unidades linguísticas convocadas, podemos observar pelos títulos que há uma preferência pelo uso do particípio passado, embora com funções e construções diferentes. Nos exemplos (2) e (3), os títulos iniciam-se com um particípio passado, de um verbo transitivo (detido) que tem uma função passiva. Em ambos os exemplos e de acordo com Duarte (2006), a interpretação da informação nestas construções privilegia a transição expressa pelo verbo de ação, neste caso, a detenção.

Ainda no exemplo (3), encontramos um pronome relativo que introduz uma frase relativa restritiva, enquanto no exemplo (2), o adjetivo suspeito seleciona uma frase completiva não finita, introduzida pela preposição de, que funciona como complemento do adjetivo.

Diferentemente, no exemplo (4), encontramos uma construção passiva adjetival em que o particípio passado do verbo encontrar tem uma função copulativa. As construções passivas adjetivais têm como função focalizar o estado resultante da transição referida pela ação, neste caso "morta". Para além disso, observa-se igualmente a presença dos adjetivos "leve, simples e barato", que funcionam como modificadores restritivos do nome vestido. A utilização desses adjetivos cria um juízo de valor relativamente ao vestido e à pessoa que o vestia, ultrapassando, assim, o domínio estritamente factual preconizado pelo género notícia e entrando num outro nível da construção da peça jornalística, a saber a transmissão de uma opinião.

Em suma, a análise mostra que há um predomínio do uso das construções frásicas com particípio passado. Esta preferência pelo particípio passado é, como vimos, uma forma de focalizar a informação sobre o objeto ou a transição da ação.

Observemos agora exemplos de notícias, em particular do corpo de texto, extraídos dos jornais (Jornal de Notícias e da Agência Lusa):

(5) Uma mulher, de 45 anos, foi morta a tiro, terça-feira de manhã, nas Angras do Norte em Esgueira, Aveiro. Tudo indica trata-se de um caso passional. $O$ agressor tentou suicidar-se mas falhou. Foi hospitalizado em estado grave. JN 23/07/2008

(6) Homicídio: Terceira mulher morta à facada em seis dias. Maria era vítima de agressões frequentes e o homicida já tinha sido condenado por violência doméstica. JN 06/08/2010

(7) Uma mulher foi hoje morta por esfaqueamento em Chelas, Lisboa, alegadamente pelo ex-companheiro, que se pôs em fuga e ainda está a monte, segundo fonte da Polícia de Segurança Pública. LUSA 14/08/2013

Se compararmos os exemplos (2), (5) e (7), podemos observar que o uso do particípio passado em tempos compostos - associado à voz passiva sintática - é também a construção que associa mais informação na mesma frase. Nestes exemplos, a informação do local e da data (5 e 7), bem como do agente introduzido pela preposição por, que na ativa é sujeito da frase, surge como informação complementar ao verbo. Todavia as construções passivas adjetivais (2), (3), (4) e (6) estão associadas a um menor conteúdo informativo.

Podemos, pois, distinguir o uso destes particípios de acordo com o texto em que se insere: as construções passivas adjetivais - associadas a um menor conteúdo informativo - ocorrem com mais frequência nos títulos das notícias. Enquanto o particípio passado em tempos compostos - associados a um maior conteúdo informativo - ocorrem com mais frequência no corpo da notícia.

Nos casos (4), (5) e (7) o foco é a mulher e nos casos (2) e (3) é o agressor que surge referenciado como "suspeito" e "homem". A forma como é mencionada a localização (na via pública ou na mala de viagem), para não falar na necessidade de descrever o vestido que a vítima usava aquando do crime.

Para além do exposto anteriormente, verificamos, igualmente, que no jornal Público a notícia surge na secção "sociedade" e no JN em "justiça", embora o jornal Público possua uma secção intitulada "justiça". 


\subsection{Presença de padrões linguísticos}

Tal como já foi referido anteriormente, o que segue perspetiva a deteção e extração de padrões linguísticos.

Num período da história em que a proliferação de dados textuais é abundante e a necessidade de gerir e processar estes dados se torna fulcral, a procura de padrões linguísticos em notícias de femicídios viabiliza uma forma de extrair informação linguística sobre a verbalização da violência, bem como compreender se há presença (ou não) de indicadores de estereótipos e de sistemas ideológicos que veiculam atitudes sociais de aceitação e/ou condenação dos intervenientes do femicídios.

Num primeiro momento, extraímos a informação relativa à frequência das unidades lexicais simples e, posteriormente, das unidades lexicais complexas e também das unidades lexicais que coocorrem.

E num segundo momento fizemos uma análise, de caráter descritiva, com o objetivo de elencar a tipologia destes padrões.

Como referido, nos casos exemplificados foi possível extrair um conjunto de informação relativa a vários campos, desses campos verificamos que a informação sobre a vítima, sobre o que aconteceu e sobre o agressor era predominante e estava presente em todos os dados textuais recolhidos e analisados. Assim, organizamos os dados de acordo com o campo lexical dos polos dominantes - paciente (vítima), ação (crime) e agente (agressor). Para cada polo foi possível identificar uma constelação lexical própria com características ligeiramente distintas sobre o tipo de informação, se a mesma era constante ou complementar (ou seja, nem sempre presente), que apresentamos de seguida.

- Polo paciente - vítima

Para este polo, verificamos que a vítima é sempre mencionada através de uma nominalização. Identificamos, que as unidades lexicais usadas para mencionar o paciente podem ser de dois grandes tipos, um apontando para a humanização da vítima; outro apontado para a sua desumanização.

A humanização da vítima é feita através do uso de nominalizações do tipo "mulher, vítima, esposa, namorada, companheira, ex-" que apelam ao lado emocional do leitor em ver a vítima como seu semelhante através de uma construção referencial in absentia - retomando aqui, num sentido amplo, a expressão de Fonseca (1996) - ou seja, essas nominalizações convocam o papel social da vítima, o que era e não será mais.

Em contrapartida, a desumanização é realizada através de nominalizações como "corpo, cadáver", promovendo uma leitura distanciada da vítima, ou seja, não é considerada uma pessoa, mas um "ser sem vida".

A informação relativa à humanização/desumanização da vítima é sempre mencionada na notícia. No entanto, nominalizações como: idade, estado civil, profissão, descendência, antecedentes, ou até mesmo a menção do nome próprio, são consideradas complementares, pois não surgem em todas as notícias.

Os resultados das nossas análises revelam algumas fragilidades no modo como a língua é usada e na forma como o texto é construído, em particular no que toca à preservação da presunção de inocência dos envolvidos, no rigor da informação que surge no corpo da notícia e na presença de estereótipos sociais.

\section{Caso 2}

Nos exemplos (8), (9) e (10) extraídos de diversos jornais, podemos observar a forma como é noticiado o femicídio que envolve mulheres que possam ou não ser prostitutas em diversos jornais. 


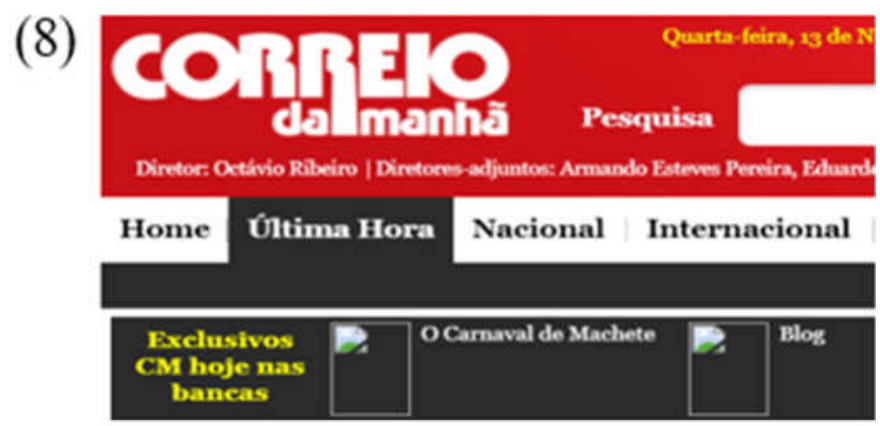

Felgueiras

\section{Prostituta morta}

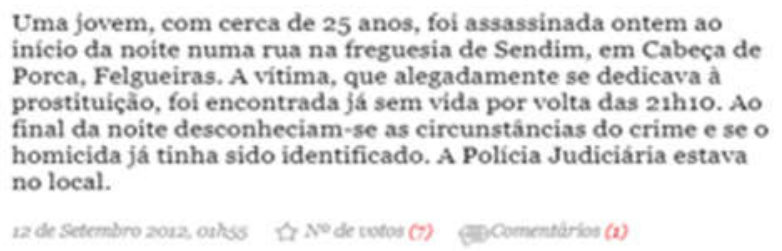

No exemplo (8), o jornal menciona taxativamente no título que a vítima é uma prostituta, apesar de no corpo da notícia ser utilizado o advérbio "alegadamente", modificador apositivo do nome "vítima", que tem como função modalizar a caracterização que é feita da vítima. Embora a notícia seja breve são igualmente referidas a idade, a localização do crime e alguns aspetos temporais. 


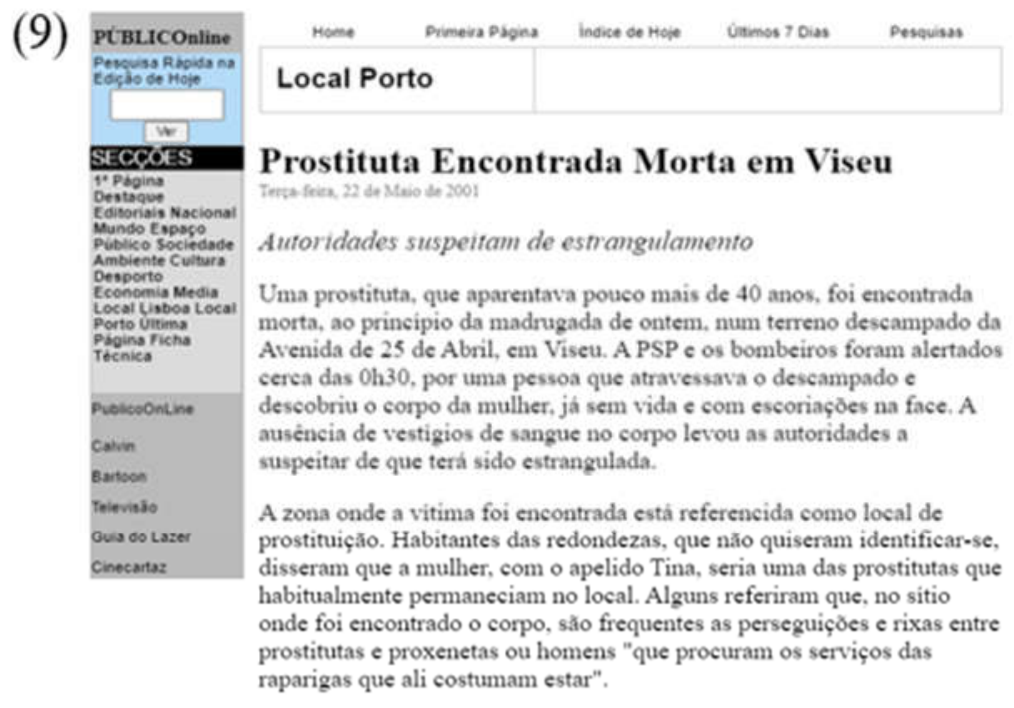

As queixas à PSP, tanto pelo barulho como pelo alergado "incómodo da presença das mulheres no local", são frequentes por parte de moradores e da direcçăo da Escola de Alves Martins, um dos maiores

estabelecimentos de ensino secundário da cidade. Aliás, a direcçăo da escola tem-se queixado também de alguma prostituição masculina no local.

Fonte da PSP disse ao PÚBLICO que esta já não é uma situação nova e que é de "dificil solução". "Como não é possivel apanhar as pessoas em flagrante delito, de que é que elas podem ser acusadas? Resta-nos patrulhar intensamente o local e o movimento desaparece, mas volta algum tempo depois", lamentou a mesma fonte. J.G.L.

No exemplo (9) o substantivo “prostituta", referido no título e inicia o corpo da notícia. A cadeia anafórica construída para referir a vítima ao longo do texto é instituída pelos seguintes substantivos, citados sequencialmente em função da posição na qual surgem na notícia: "prostituta" (no título), "uma prostituta" (no corpo da notícia), "encontrada morta", "o corpo da mulher", "a vítima", "a mulher", "Tina", "uma das prostitutas", “o corpo". Observa-se, portanto, que o primeiro signo para caracterizar a vítima é "prostituta", repetido três vezes na notícia. Para além disso, verifica-se um desvio relativo ao enfoque da notícia (assassinato de uma mulher) a partir do segundo parágrafo, continuando no terceiro parágrafo. Ambos os parágrafos incidem sobre a situação do local com relação à questão da prostituição (queixa das pessoas, soluções por parte da PSP). Pelo exposto, depreende-se que o femicídio deixa de ocupar o lugar central desta notícia, ao contrário do expectável. De facto, iniciada pelo papel social da vítima, tem como desenvolvimento a temática da prostituição. 
(10)

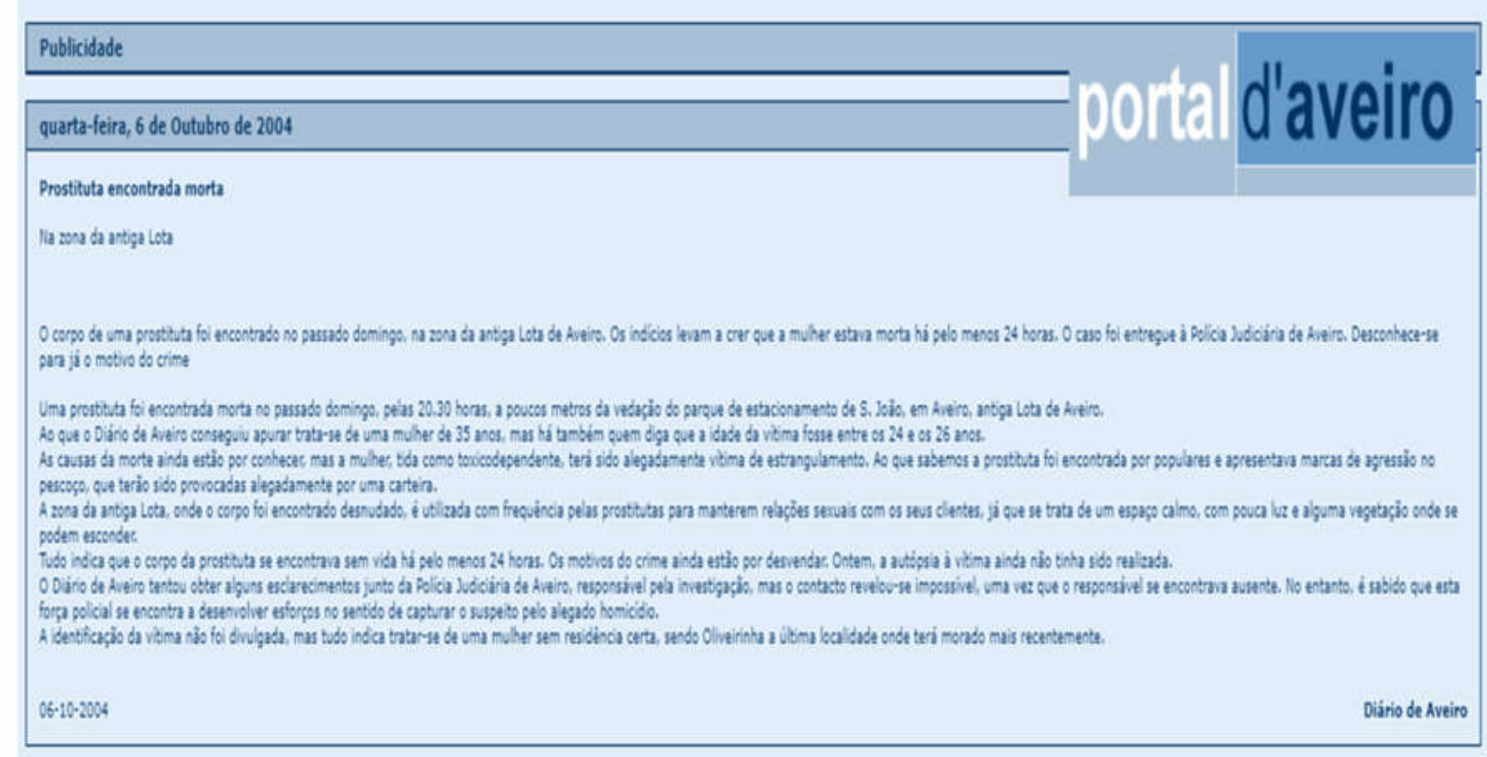

Tal como nos exemplos (8) e (9), o título desta notícia refere o papel social da vítima e a textualização do femicídio inicia-se a partir do referente "prostituta". A partir desse ponto é constituída a cadeia anafórica através das seguintes expressões "corpo de uma prostituta", continuando com "mulher estava morta", "uma prostituta", "uma mulher", "toxicodependente", "prostituta", "corpo", "corpo da prostituta”, "vítima”, "identificação da vítima", "mulher". São de destacar outros aspetos ao nível do conteúdo temático, nomeadamente o facto de a vítima não ter residência certa e os pormenores relativos à zona onde o corpo foi encontrado "espaço calmo, com pouca luz e alguma vegetação onde se podem esconder"; este último aspeto edifica um desvio sobre o cerne da notícia.

Nos exemplos (8), (9) e (10), tendo em conta que as pessoas foram vítimas de femicídio, era de esperar que fossem referidas, deste modo, em primeira mão, e não através do papel social (profissão, ocupação), aspeto considerado como informação adicional e não como essencial para a compreensão do acontecimento.

A importância dada ao papel social da vítima mostra que existe um juízo de valor em relação indivíduo. O que estes exemplos mostram, é que o atenuamento ou agravamento é modalizado através da quantidade de informação disponibilizada e da forma como ela é textualizada.

- Polo ação - crime

Para o polo ação, observamos que a forma de mencionar o crime tende para a utilização de nominalizações jurídicas, tais como “crime, crime passional, homicídio". Também neste polo existem duas formas de mencionar a ação envolvida: (i) quando não se conhece em concreto a forma exata do crime, são usadas construções do tipo [nome + adjetivo modificador restritivo] ("mulher morta, mulher encontrada"); (ii) quando se sabe em concreto, as expressões verbais são diversas, podem ser neutras ("assassinada", "foi morta"); mais específicas (morta com (tiros)/à machadada); ou até mesmo mais explícitas (baleada, alvejada, carbonizada, queimada), textualizadas com o recurso à forma passiva.

Constatamos que neste polo a informação complementar é extensa. Refere-se a múltiplos e distintos aspetos como: a informação relativa à localização do crime (com maior ou menor pormenor geográfico que vai 
desde a menção do concelho até ao pormenor da identificação da rua), o estado físico da vítima (detalhes sobre as consequências da agressão, quando o foco é a forma violenta, menciona-se corpo, cadáver e raramente mulher), as testemunhas (através do discurso direto ou indireto de pessoas que vivam perto da cena do crime ou de outros intervenientes, que, no entanto, não assistiram necessariamente ao crime), as autoridades (relatos oficiais).

Esta informação complementar ajudará o leitor a enquadrar o crime e a relação entre os intervenientes (a situação emocional entre os mesmos), a obter um enquadramento de episódios de violência (entre ambos, ou de um sobre o outro), a compreender a circunstância familiar atual (situação de divórcio, separação, ciúmes, recusa da vítima em fazer algo, entre outros) como explicativa do crime cometido.

- Polo agente-agressor

Para este polo verificamos que o agressor é sempre mencionado através de uma nominalização, mas com variação entre o uso de uma nominalização jurídica "alegado agressor, suspeito, pessoa, indivíduo" no sentido de respeitar a presunção de inocência e nominalizações que apontam para o papel social e afetivo/emocional deste para com a vítima "marido, namorado, ex-companheiro, ..." no sentido de humanizar o agressor. No tocante à informação complementar sobre este polo, notamos um paralelismo na informação disponibilizada à semelhança do que é feito para a vítima, o uso de nominalizações como: idade, estado civil, profissão, descendência, antecedentes, (mas neste caso nunca ou quase nunca é mencionado o nome próprio). É, todavia, fornecido posteriormente com frequência, um conjunto de informação relativa ao temperamento (violento, calmo ou reservado) e à situação atual (detido, morto, em fuga, ...).

O uso da nominalização para mencionar os intervenientes, o tipo de verbalização utilizada para descrever a ação e as nominalizações e adjetivalizações empregadas para mencionar aspetos relativos aos intervenientes e ação mostram que, para cada polo e sua constelação lexical, há duas zonas, uma que podemos associar a aspetos factuais e outra tendencialmente sensacionalista pelo número de informações complementares que é fornecido e que permite ao leitor inferir uma série de leituras paralelas e que em alguns casos são um indicador quer da atitude social do meio de comunicação (ou do jornalista) quer daquilo que o jornal espera ou acredita que é a expectativa da comunidade, como vimos nos exemplos anteriores.

De seguida, apresentamos um esquema relativo aos polos - vítima, agressor e crime - onde se pode visualizar a distribuição dos padrões linguísticos. 


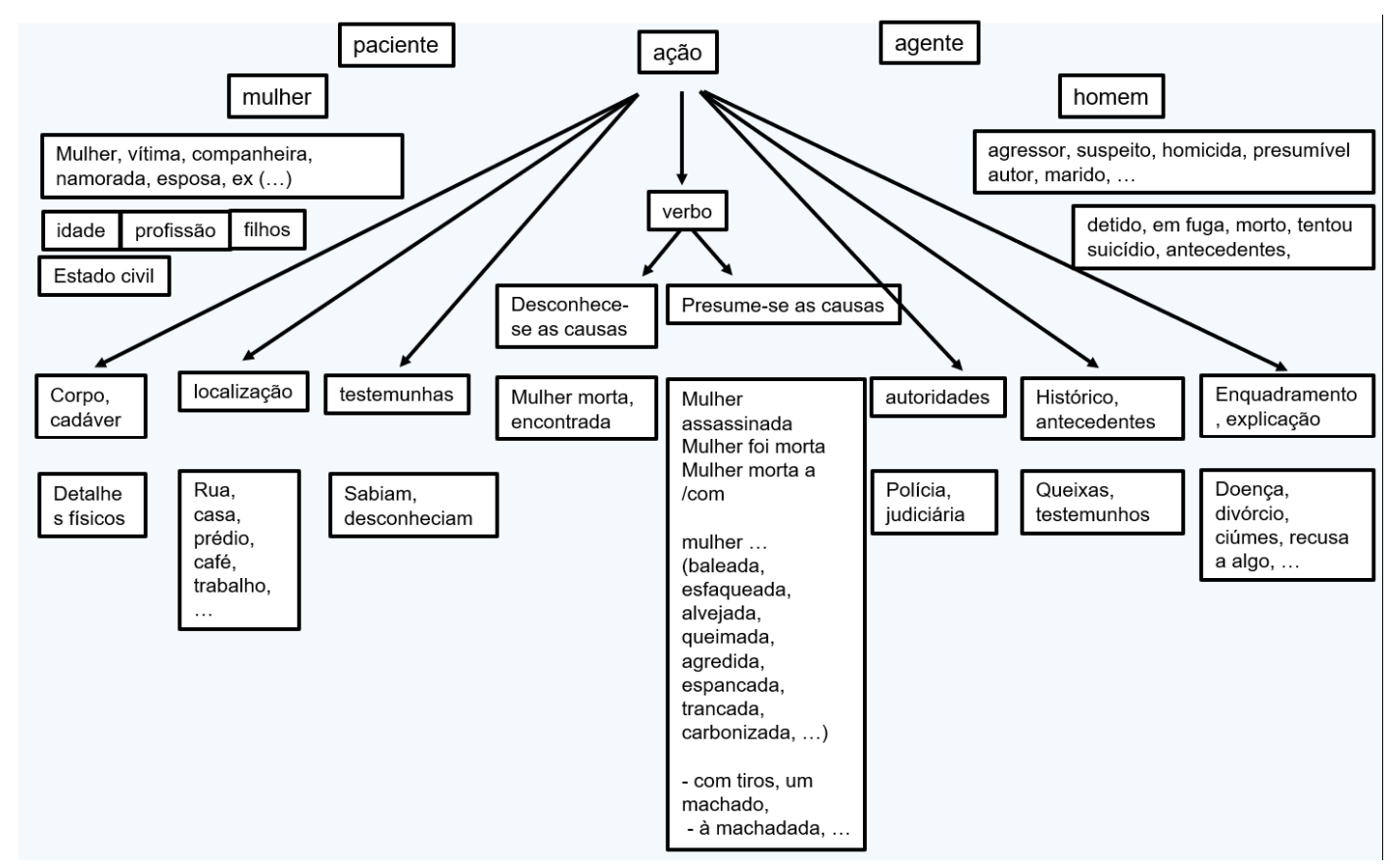

Figura 2. Distribuição da informação (necessária e complementar) referente aos polos dominantes nos textos noticiosos

O léxico fornece também pistas sobre as representações sociais, culturais e legais que projetamos na sociedade. Por exemplo, o uso de "alegado suspeito" e de uma terminologia associada ao plano jurídico ajuda a respeitar a privacidade dos envolvidos e a presunção de inocência a que os jornalistas são obrigados. Por outro lado, a menção de detalhes acessórios e que, em alguns casos, não acrescentam conteúdo informativo factual ao crime reportado permite um conjunto de leituras de culpabilização da vítima (já tinha sido vítima de maustratos, mas continuava a viver com o agressor; que tipo de roupa utilizava aquando do crime; a disparidade de idades entre os envolvidos - ênfase nos casos de mulheres mais velhas do que os companheiros; ter filhos de outros relacionamentos anteriores, papel social) ou de desculpabilização do agressor (era uma pessoa calma, estava deprimido por causa do divórcio).

Pelo exposto depreende-se que são construídos vieses linguísticos, em particular uma culpabilização da vítima e uma desculpabilização do agressor, que, ao serem disseminadas pelos meios de comunicação social, se transpõem em representações estereotipadas e ideológicas, passando de uma ideologia do quotidiano, construída pelos textos jornalísticos e respetivos comentários quotidianos,, para um sistema ideológico construído, cristalizado e enraizado na atividade jurídica, ética e moral. Consequentemente pode haver modelação da perceção geral e de julgamentos e de julgamentos em casos de violência doméstica e de femicídio. Veja-se, a título de exemplo, um acórdão, no qual o juiz Joaquim Neto de Moura censurou moralmente uma mulher, vítima de violência doméstica, minimizando a culpa do agressor ou ainda o caso do julgamento de Manuel Maria Carrilho, no qual a juíza, Joana Ferrer Antunes, sempre se dirigiu à vítima, Bárbara Guimarães, pelo primeiro nome "Bárbara" e, ao agressor, por "Professor"; para além de ter declarado o seguinte: "Causa- 
me alguma impressão a atitude de algumas mulheres vítimas de violência, algumas das quais acabam mortas." e ainda dirigindo-se à vítima "Pois eu censuro-a!"

\section{Reflexões finais}

Parcos são os trabalhos que incidem sobre as notícias relativas à violência e seu impacto nos sobreviventes destes crimes, em particular e na sociedade portuguesa, em geral. Assim, movidos pela vontade de contribuir para a erradicação das formas de violência contra a mulher, através de uma melhor compreensão sobre as notícias de femicídio e o seu impacto a nível social, procedemos à constituição de um corpus de notícias relativas à temática em questão e à sua análise, cruzando as áreas da linguística do texto e do discurso e a linguística de corpus, para determinar a existência de padrões linguísticos e seus impactos a nível da construção e perpetuação de representações estereotipadas.

Da nossa análise, chegamos à determinação da existência de três polos dominantes: paciente/mulher, agente/homem e ação/crime, bem como de uma constelação lexical própria com interseções de vocabulário entre as mesmas e por vezes alguma dispersão de vocabulário consoante determinados detalhes muito específicos das notícias. Através da observação apenas do padrão lexical e textual básicos é possível verificar que o tipo de vocabulário utilizado para nomear e descrever os envolvidos permite distingui-los socialmente; o padrão textual dá pistas para entender como as interpretações subjetivas podem surgir, permitindo quer uma culpabilização da vítima, quer uma desculpabilização do agressor. De facto, os resultados das nossas análises apontam para algumas fragilidades no modo como a língua é usada e na forma como o texto é construído, em particular no que toca à preservação da presunção de inocência dos envolvidos, no rigor da informação que surge no corpo da notícia e na presença de estereótipos sociais. Para além disso, o presente artigo evidenciou a possibilidade de detetar padrões linguísticos que convocam a organização do conteúdo informativo de modo polarizado ou ainda interpretações emocionais relacionadas com o papel social da vítima e do agressor, bem como a construção de representações estereotipadas.

Numa ótica de promover uma abordagem mediadora entre o trabalho académico e a sociedade civil, no que toca à compreensão da representação da violência nos meios de comunicação, estamos em crer que este estudo pode contribuir para uma consciencialização e uma sensibilização dos criadores de conteúdos noticiosos, cujo trabalho é regido pela Lei da Imprensa, pelo Estatuto do Jornalista e pelo Código Deontológico, bem como dos responsáveis associativos que cuidam de vítimas de violência.

\section{Referências:}

Adam, Jean-Michel (1999). Linguistique textuelle. Des genres de discours aux textes. Paris: Éditions Nathan. Adam, Jean-Michel (2008). A linguística textual. Introdução à análise textual dos discursos. São Paulo: Cortez Editora

Adam, Jean-Michel (2015). Introduction aux problèmes du texte. In. ADAM, J.-M. (Dir.). Faire texte. Frontières textuelles et opérations de textualisation. Besançon : Presses Universitaires de Franche-Comté, pp. 11-33.

Alvares, Cláudia \& Veríssimo, Iolanda (2016). Practice what you preach: Deconstructing gender equality in portuguese media. In K. Ross, Padovani, \& Claudia (Edits.), Gender Equality and the Media: A Challenge for Europe, Routledge. pp. 158-170.

APAV (2019). Estatísticas APAV Relatório Anual 2019. Disponível em https://apav.pt/apav_v3/images/pdf/Estatisticas_APAV-Relatorio_Anual_2019.pdf

${ }^{2}$ Veja-se aqui a notícia do Público: https://www.publico.pt/2016/02/15/sociedade/noticia/mulheres-juristas-contra-a-forma-como-juiza-sedirigiu-a-barbara-guimaraes-1723406 
Beukeboom, Camiel J. \& Burgers, Christian (2017) Linguistic bias. In Oxford Encyclopedia of Intergroup Communication. Oxford: Oxford University. DOI: 10.1093/acrefore/9780190228613.013.439.

Borchmann, Simon, Levisen, Carsten \& Schneider, Britta (Eds.) (2019). Biases in Linguistics. Elsevier. In Language Sciences, No. November 2019, special issue, Vol.76. Disponível em https://www.sciencedirect.com/journal/language-sciences/vol/76/suppl/C

Braber, Natalie (2014). Representation of domestic violence in two british newspapers: The Guardian and The Sun, 2009-2011. English Language Research Journal, pp. 86-104.

Bronckart, Jean-Paul (1997). Activité langagière, textes et discours: pour un interactionnisme socio-discursif. Paris: Delachaux et Niestlé.

Bronckart, Jean-Paul (2005). Os gêneros de Textos e os Tipos de Discurso como Formatos das Interações Propiciadoras de Desenvolvimento. In Análise do Discurso, Menendez, F. (ed). Lisboa: Hugin, pp. 37-39.

Carvalho, Danielle Soares (2013). Jornais Populares: O retrato da mulher vitima de violência doméstica nos títulos do Correio da Manhã e Folha de Pernambuco. Faculdade de Ciências Sociais e Humanas da Universidade Nova de Lisboa.

Chesney-Lind, Meda \& Chagnon, Nicholas (2017). Media representations and domestic violence. In Oxford research encyclopedias, pp. 1-16.

Coimbra, Artemisa (2007). Crónicas de mortes anunciadas - Violência doméstica, imprensa e questões de género em articulação com a educação da cidadania. Faculdade de Psicologia e Ciências da Educação da Universidade do Porto.

Coutinho, Maria Antónia (2005). Para uma linguística dos géneros de texto. In Diacrítica, n. ${ }^{\circ}$ 19, vol. 1, pp. 7388. Disponível em: http://cehum.ilch.uminho.pt/cehum/static/publications/diacritica 19-1.pdf

Coutinho, Maria Antónia (2019). Texto e(m) linguística: Teorias, cruzamentos, aplicações. Lisboa: Edições Colibri.

Coutinho, Maria Antónia \& Miranda, Florencia (2009). To describe textual genres: problems and strategies. In Genre in a Changing World, ed. Bazerman, Charles, Bonini, Adair, and Figueiredo, Débora, pp. 1-528. Fort Collins, Colorado: The WAC Clearinghouse and Parlor Press. pp. 35-55 Disponível em http://wac.colostate.edu/books/genre/.

Duarte, Inês (2006). A família das construções inacusativas. In Gramática da Língua Portuguesa. Lisboa: Caminho.

Fairclough, Norman (1989/1994) Language and Power. London: Longman.

Fonseca, Fernanda Irene (1996). Deixis e pragmática linguística. In Introdução à Linguística Geral e Portuguesa, Org. de Isabel Hub Faria, Emília Ribeiro Pedro, Inês Duarte, Carlos A.M.Gouveia, Ed. Caminho, Lisboa, (437-445).

Gonçalves, Matilde \& Magalhães, Miguel (2019). Corpus e géneros textuais nas práticas de divulgação de ciência ou as novas hierarquias na construção do conhecimento. In Revista da Associação Portuguesa de Linguística, pp.145-157.

Gonçalves, Matilde (2014). Similitudes et différences textuelles dans les genres numériques : blog et site web. In Studii de lingvistica 4 (4): 75-91._Disponível em http://studiidelingvistica.uoradea.ro/docs/42014/articole\%20pdf\%20SL4/Goncalves.pdf

Leal, Audria \& Gonçalves, Matilde (2007). Géneros ficcionalizados e identidade de género. In Actas do $4^{\circ}$ SIGET, Tubarão - $\quad$ Santa Catarina, $\quad$ pp.696-707. $\quad$ Disponível em http://linguagem.unisul.br/paginas/ensino/pos/linguagem/eventos/cd/Port/25.pdf

Magalhães-Dias, Carolina \& Lobo, Soraia (2016). Changing representations of intimate partner femicides by a portuguese newspaper (2006 and 2014) from episodic to thematic frames. Ex aequo, 34, pp. 93-108.

Maltais, Robert (dir.) (2010). L'écriture journalistique sous toutes ses formes. Montréal: Presses de l'Université de Montréal. 
Marcuschi, Luiz Antônio (2008). Produção textual, análise de gêneros e compreensão. São Paulo: Parábola Editorial.

Martinez, William \& Barbosa, Sílvia (2018). Building a Portuguese oenological dictionary: from corpus to terminology via co-occurrence networks. In 18TH EURALEX INTERNATIONAL CONGRESS Lexicography in global contexts - Ljubljana, (Slovenia): 17-21 July 2018. Disponível em http://euralex.org/publications/building-a-portuguese-oenological-dictionary-from-corpus-to-terminologyvia-co-occurrence-networks/

Neves, Sofia, Gomes, Sílvia \& Martins, Dircelena (2016). Narrativas mediáticas sobre o femicídio na intimidade: análise de um jornal popular português. Ex aequo, 34, pp. 77-92.

Penedo, Cristina (2003) (2003). O crime nos media. Impacto e valor simbólico das histórias transgressivas. Media \& Jornalismo, 3, pp. 89-102.

Rastier, François (2001). Arts et Sciences du Texte. Paris: P.U.F.

Rodigou, Maite, Nazar, Maria, Monserrat, Sofía \& Hunt, Laura (2007). La violencia hacia las mujeres en los médios de comunicación, 1-42. (M. Rodigou, Ed.) CISCSA.

Simões, Rita (2007). A violência contra as mulheres nos media. Coimbra: Coimbra Editora.

Souza, Juliana (2014). A invisibilidade das mulheres nos media: quando a representação de género define o sexo da notícia. Media \& Jornalismo, 14, pp. 91-103.

Swales, John (1990). Genre Analysis. English in Academic and Research Settings, Cambridge: Cambridge University Press.

Taylor, Catherine \& Sorenson, Susan (2002). The nature of newspaper coverage of homicide. Injury Prevention, 8, pp. 121-127.

Toledo, Patsilí \& Lagos, Claudia (2014). The media and gender-based murders of women: notes on the cases in Europe and Latin America, Heinrich Boll Foundation, 24 julho 2014. Disponível em https://eu.boell.org/en/2014/07/24/media-and-gender-based-murders-women-notes-cases-europe-andlatin-america201

van Dijk, Teun (2014) Ideology. Disponível em http://www.discourses.org/OldArticles/Ideology.pdf

Volochinov, Valentín (1929/1977). Le marxisme et la philosophie du langage. Paris: Minuit.

Wilcox, Paula (2008). Constructing the victim and perpetrator of domestic violence. Issues in the social sciences, 7, pp. 76-98.

Wosniak, Jessica \& McCloskey, Kathy (2010). Fact or fiction? Gender issues related to newspaper reports on intimate partner homicide. Violence against women, 16 (8), pp. 934-952. 